\title{
Successful orthodontic treatment of Class II division 1 malocclusion in a non growing patient : A case report
}

\author{
Ali MW ${ }^{1}$ BDS, DDS, FCPS and Hossain MZ² BDS, PhD
}

\begin{abstract}
Aim \& objectives of the present case report was to evaluate the management of skeletal Class II division 1 malocclusion in non growing patient with extraction of upper first premolars. Clinical and cephalometric evaluation revealed skeletal Class II division 1 malocclusion with severe maxillary incisor proclination, convex profile, average mandibular plane angle, incompetent lips, increased overjet and overbite. After extraction of upper 1st premolars, canine retraction was done which was followed by retraction of severely proclined upper anterior teeth by judicious control of third order bend in rectangular stainless steel arch wire with "V" loop . For anchorage management, intra oral anchorage with tip back \& toe in bends in stainless steel arch wire was satisfactory. Following treatment marked improvement in patient's smile, facial profile and lip competence were achieved and there was a remarkable increase in the patient's confidence and quality of life.
\end{abstract}

Keywords: Class II div1 malocclusion, non growing patient, tip back, toe in bend (Bangladesh Journal of Orthodontics and Dentofacial Orthopedics, Vol. 2, No. 2, April 2012, p 41-45).

\section{INTRODUCTION}

Class II div 1 malocclusion is more prevalent than any type of malocclusion after Class I malocclusion in our country. 1,2 Over the last decade, increasing numbers of adults have become aware of orthodontic treatment and are demanding high quality treatment, in the shortest possible time with increased efficiency and reduced costs. ${ }^{3}$ Class II malocclusions can be treated by several means, according to the characteristics associated with the problem, such as anteroposterior discrepancy, age, and patient compliance. ${ }^{4}$ Methods include extraoral appliances, functional appliances and fixed appliances associated with Class II intermaxillary elastics. ${ }^{5}$ On the other hand, correction of Class II malocclusions in nongrowing patients usually includes orthognathic surgery or selective removal of permanent teeth, with subsequent dental camouflage to mask the skeletal discrepancy. The indications for extractions in orthodontic practice have historically been controversial. ${ }^{6-8}$ Premolars are probably the most commonly extracted teeth for orthodontic purposes as they are conveniently located between the anterior and posterior segments. Variations in extraction sequences including upper and lower first or second premolars have been recommended by different authors for a variety of reasons..$^{9-14}$ For correction of Class II malocclusions in non-growing patients extractions can involve 2 maxillary premolars ${ }^{15}$ or 2 maxillary and 2 mandibular premolars. ${ }^{16}$ It is usually not the skeletal characteristics of a Class II malocclusion that primarily determine whether it should be treated with 2 or 4 premolar extractions but, rather, the dentoalveolar characteristics.

The extraction of only 2 maxillary premolars is generally indicated when there is no crowding or cephalometric discrepancy in the mandibular arch. ${ }^{17,18}$ Extraction of 4 premolars is indicated primarily for crowding in the mandibular arch, a cephalometric discrepancy, or a combination of both, in growing patients. ${ }^{17-19}$
Recent studies have shown that patient satisfaction with camouflage treatment is similar to that achieved with surgical mandibular advancement $\mathrm{t}^{20}$ and that treatment with two maxillary premolar extractions gives a better occlusal result than treatment with four premolars extractions. ${ }^{21}$

\section{CASE REPORT}

\section{Pretreatment assessment}

A 17 year old female reported to the Orthodontic Department at Dhaka Dental College \& Hospital with multiple complaints "my teeth stick out", "I am unable to close my lips" "I feel embarrassed when I laugh". She gave a history of previous orthodontic treatment by a quack where an attempt was made to retrocline protruded upper teeth by upper removable appliance with proximal disking of upper anterior teeth. Extra oral examination revealed a mesocephalic symmetrical face, convex hard and soft tissue profile, lip trap and an acute nasolabial angle. The patient showed a good range of mandibular movements and no TMJ symptoms. Intra oral examination revealed that the patient had a full Class II molar and canine relationship, excessively proclined maxillary incisors with an overjet of $11 \mathrm{~mm}$ and traumatic deep overbite. (Fig 1) Cephalometric examination revealed Class II skeletal relation with severe maxillary incisor proclination with horizontal growth pattern. (Fig 2) Although the underlying sagittal jaw discrepancy was severe, the selective extraction of two permanent maxillary first premolar teeth was considered acceptable. Our treatment objective focused on the chief complaint of the patient, and the treatment plan was individualized based on the specific treatment goals. 

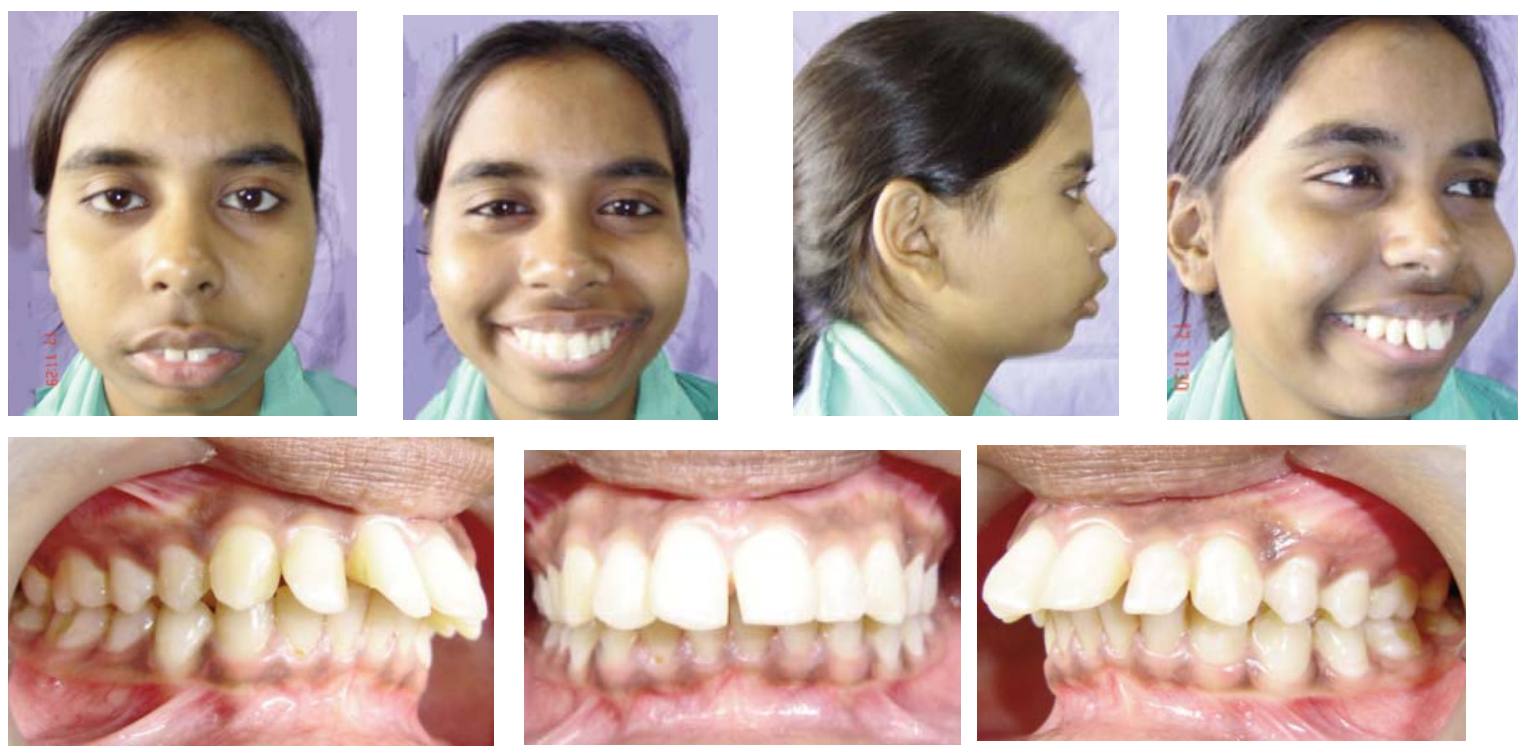

Figure 1. Pretreatment extra oral \& intra oral photographs

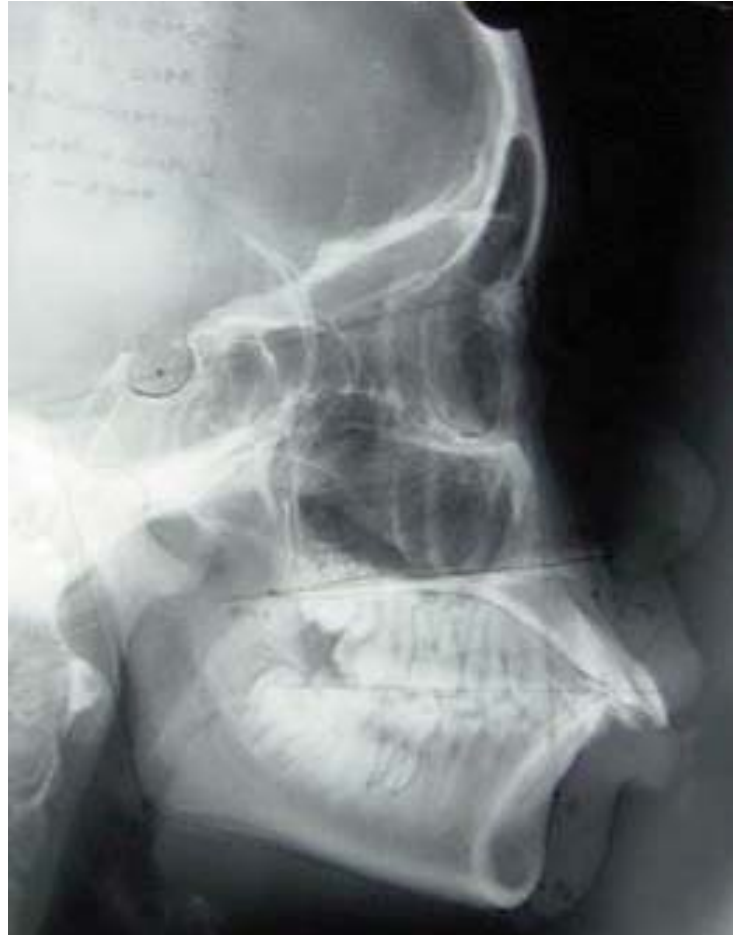

Figure 2. Pre treatment lateral Cephalogram

\section{DIAGNOSIS}

Skeletal Class II division 1 malocclusion with severe maxillary incisor proclination, convex profile, average mandibular plane angle, lip trap, incompetent lips, increased overjet \& traumatic deep overbite.

\section{TREATMENT OBJECTIVES}

1. Achieve lip competence and reduce the labiolmental fold.

2. Develop an ideal overjet \& overbite.

3. Correct the anteroposterior relationship.

4. Achieve occlusal intercuspation with a Class I canine relationship.

5. Improve the profile and facial esthetics.

\section{TREATMENT PLAN}

1. Extraction of maxillary first premolars.

2. Alignment \& leveling of upper \& lower arches.

3. Retraction of upper canines.

4. Correction of deep overbite.

5. Upper arch contraction.

6. Final settling of the occlusion and arch coordination.

\section{TREATMENT PROGRESS}

The maxillary first premolars were extracted. The first molars were banded and the maxillary and mandibular teeth were bonded from premolar to premolar with a $0.018 \times 0.025$ standard edgewise brackets. Retractions of upper canines was done in 0.016 inch round stainless steel arch wire with stop loops and tip back and toe-in anchorage bends. 

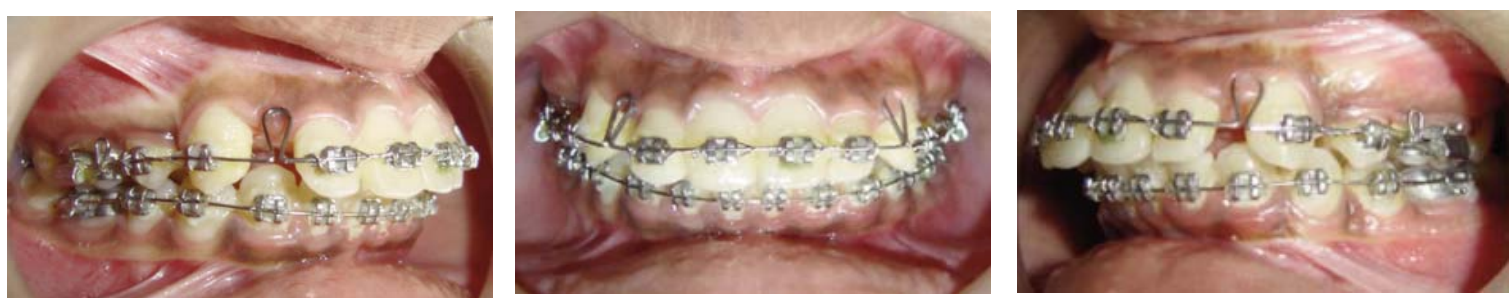

Figure 3. After Canine retraction upper arch contraction started (right buccal, frontal and left buccal view)

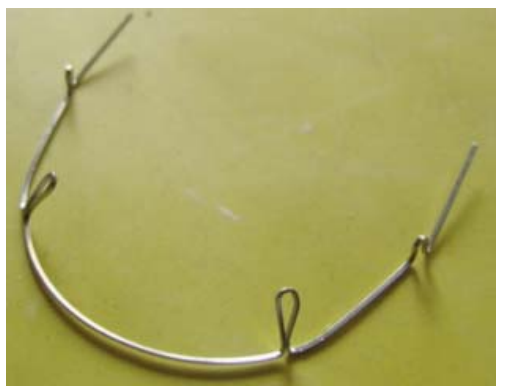

Figure 4. Rectangular (0.017 X 0.025) arch wire with "V" loop for upper arch contraction
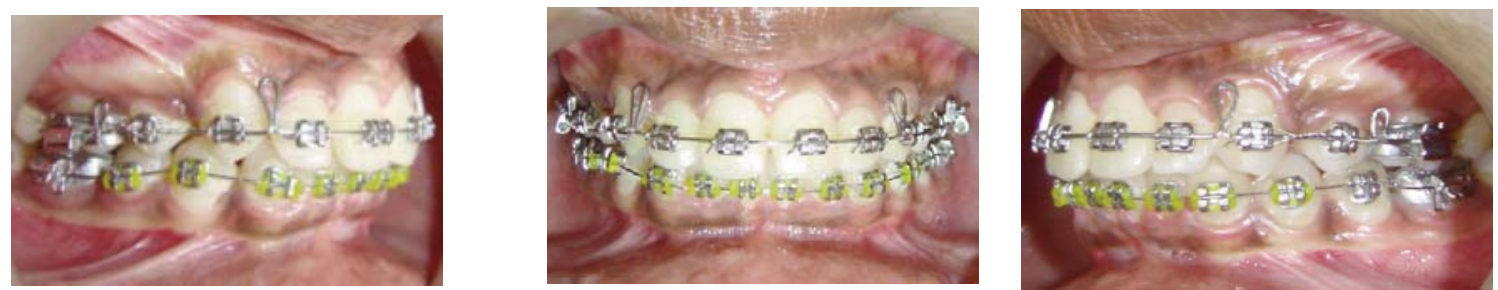

Figure 5. Completed upper arch contraction(Left buccal, frontal and right buccal view)

Arch contraction and closure of extraction spaces in upper arch was done by rectangular $(0.017 \mathrm{X} 0.025$ inch) Stainless Steel archwire with "V" loops with proper control of third order bend 'Torque'. (Fig. 5 \& 6 ). Final settling of occlusion was done with proper interdigitation, inclination, angulation, ideal overjet and overbite. Proximal recontouring of upper incisors was done by composite resin due to proximal disking in previous orthodontic treatment. Debonded and retention was given by upper \& lower Hawley's retainers. Patient was advised to follow up in retention period.

\section{Post treatment assessment:}

Lip competence and a straight profile were achieved, improving the patient's facial appearance. A functional occlusion with normal overjet and overbite; Class I canine relationship was achieved (Fig. 7, 8 \& 9). Duration of the treatment was 21 months. The patient and her parent were very happy with complete satisfaction.
Table 1: Cephalometric Analysis

\begin{tabular}{lccc}
\hline Variables & $\begin{array}{c}\text { Reference } \\
\text { measurement }\end{array}$ & Pretreatment & Post treatment \\
\hline SNA & 82 & 86 & 84 \\
SNB & 80 & 80 & 80 \\
ANB & 2 & 6 & 4 \\
IIA & 130 & 106 & 125 \\
GoGn to SN & 32 & 30 & 33 \\
U1 - SN & 104 & 115 & 104 \\
\hline
\end{tabular}


Figure 6. Pre \& post treatment extra oral photographs
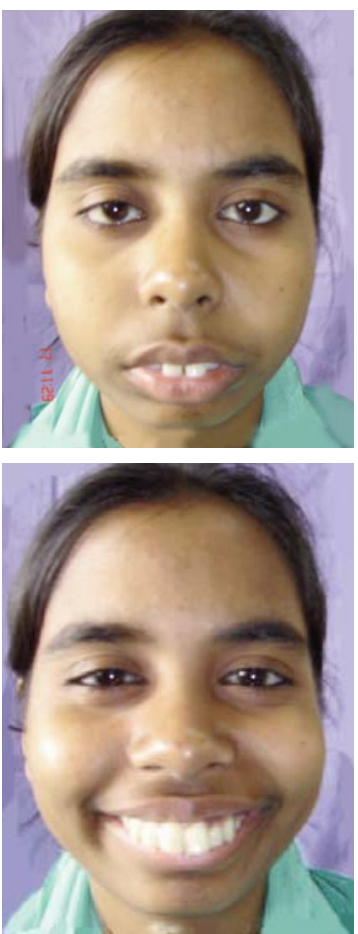

Pretreatment
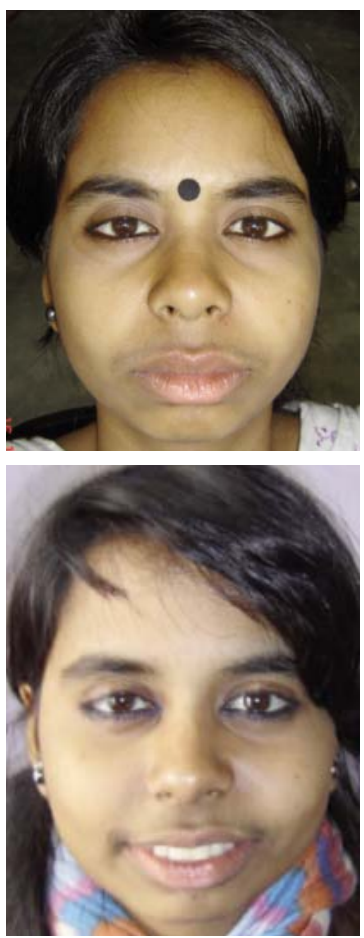

Post treatment
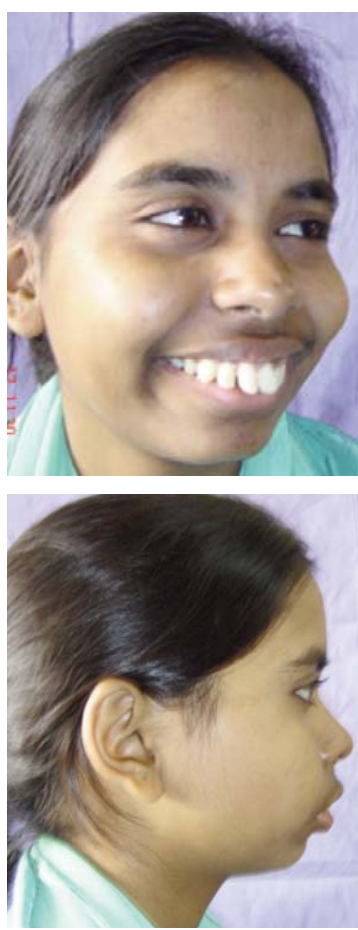

Pretreatment
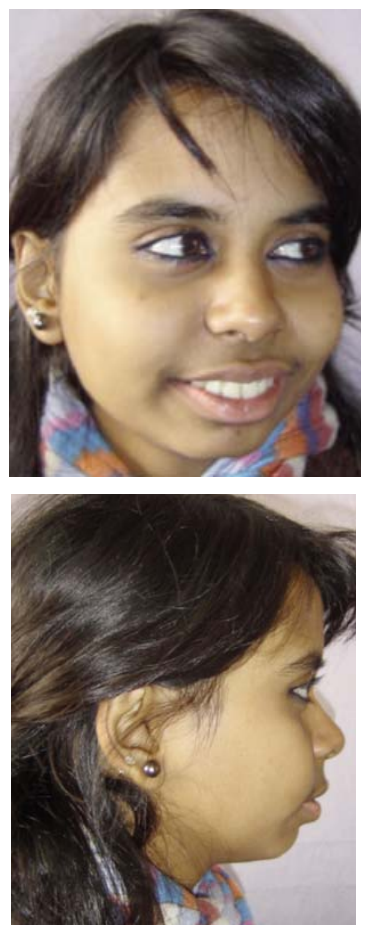

Post treatment

Figure 7: Pre \& Post treatment intra oral photographs
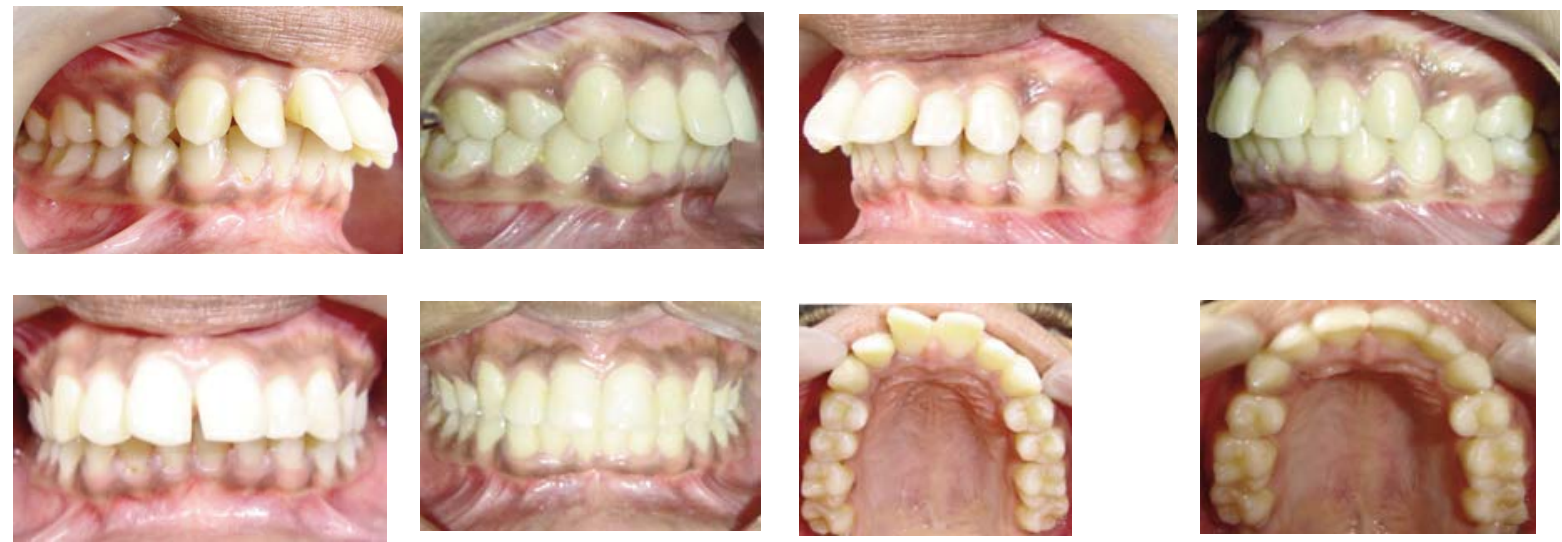

Pretreatment

Post treatment

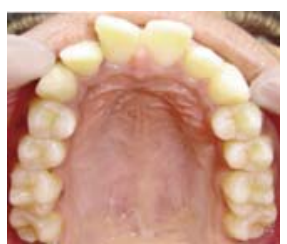

Pretreatment

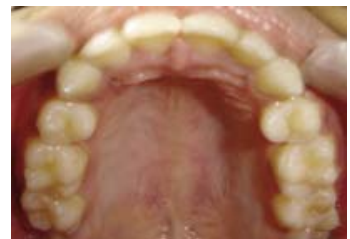

Post treatment 


\section{DISCUSSION}

Patient had improved smile and profile after orthodontic treatment. Upper incisors were retracted to achieve normal incisor inclinations, overjet and overbite. Bilateral Class I canine relation was achieved with maximum intercuspation. The case was successfully managed by contemporary orthodontic technique with intra oral anchorage incorporated in archwire.

\section{CONCLUSIONS}

Camouflage treatment of Class II malocclusion in adults is challenging. Extractions of premolars, if undertaken after a thorough diagnosis leads to positive profile changes and an overall satisfactory facial aesthetics. A well chosen individualized treatment plan, undertaken with sound biomechanical principles and appropriate control of orthodontic mechanics to execute the plan is the surest way to achieve predictable results with minimal side effects.

\section{REFERENCES}

1. Hossain MZ et al, Prevalence of malocclusion and treatment facilities at Dhaka Dental College and Hospital. Journal of Oral Health, vol: 1, No. 1, 1994

2. Ahmed $\mathrm{N}$ et al, Prevalence of malocclusion and its aetiological factors. Journal of Oral Health, Vol. 2 No. 2 April 1996

3. Khan RS, Horrocks EN. A study of adult orthodontic patients and their treatment. Br J Orthod,18(3):183-194; 1991.

4. Salzmann JA. Practice of orthodontics. Philadelphia: J. B. Lippincott Company; p. 701-24;1966.

5. McNamara, J.A.: Components of Class II malocclusion in children 810 years of age, Angle Orthod, 51:177-202; 1981.

6. Case C S. The question of extraction in orthodontia. American Journal of Orthodontics, 50: 660-691; 1964.

7. Case C S. The extraction debate of 1911 by Case, Dewey, and Cryer. Discussion of Case: the question of extraction in orthodontia. American Journal of Orthodontics, 50: 900-912; 1964.

8. Tweed C. Indications for the extraction of teeth in orthodontic procedure. American Journal of Orthodontics 30: 405-428; 1944.

9. Staggers J A. A comparison of results of second molar and first premolar extraction treatment. American Journal of Orthodontics and Dentofacial Orthopedics, 98: 430-36; 1990.
10. Luecke P E, Johnston L E. The effect of maxillary first premolar extraction and incisor retraction on mandibular position: testing the central dogma of 'functional orthodontics'. American Journal of Orthodontics and Dentofacial Orthopedics, 101: 4-12; 1992.

11. Proffit W R, Phillips C, Douvartzidis N. A comparison of outcomes of orthodontic and surgical-orthodontic treatment of Class II malocclusion in adults. American Journal of Orthodonticsand Dentofacial Orthopedics, 101: 556-565; 1992.

12. Paquette D E, Beattie J R, Johnston L E. A long-term comparison of non extraction and premolar extraction edgewise therapy in "borderline' Class II patients. American Journal of Orthodontics and Dentofacial Orthopedics, 102:1-14; 1992.

13. Taner-Sarısoy L, Darendeliler N. The influence of extraction treatment on craniofacial structures: evaluation according to two different factors. American Journal of Orthodontics and Dentofacial Orthopedics 115: 508-514; 1999

14. Basciftci F A, Usumez S. Effects of extraction and non extraction treatment on Class I and Class II subjects, Angle Orthodontist 73: $36-42 ; 2003$.

15. Cleall JF, Begole EA. Diagnosis and treatment of Class II Division 2 malocclusion. Angle Orthod 52:38-60; 1982.

16. Strang RHW. Tratado de ortodoncia. Buenos Aires: Editorial Bibliogra'fica Argentina; 1957. p. 560-70, 657-71.

17. Bishara SE, Cummins DM, Jakobsen JR, Zaher AR. Dentofacial and soft tissue changes in Class II, Division 1 cases treated with and without extractions. Am J Orthod Dentofacial Orthop 107:28-37; 1995

18. Rock WP. Treatment of Class II malocclusions with removable appliances. Part 4. Class II Division 2 treatment. Br Dent J 168:298-302; 1990

19. Arvystas MG. Nonextraction treatment of Class II, Division 1 malocclusions. Am J Orthod 88:380-95; 1985.

20. Mihalik, C.A.; Proffit, W.R.; and Phillips, C.: Long-term followup of Class II adults treated with orthodontic camouflage: A comparison with orthognathic surgery outcomes, Am. J. Orthod. 123:266-278, 2003

21. G Janson, AC Brambilla, JFC Henriques, MR de. Class II treatment success rate in 2- and 4-premolar extraction protocols, Am. J. Orthod.125(4):472 - 479, 2004
Corresponds to:

Dr. Md. Wazed Ali BDS, FCPS

Assistant Professor \& Head

Dept. of Orthodontics

Dental Unit, Chittagong Medical College

Cell : +8801819134634, E-mail : drwazed@gmail.com 